\title{
Glucose modulates handling of apoptotic cells by mesangial cells: involvement of TGF- $\beta 1$
}

\author{
Tarnjit K Khera, John Martin, Stephen G Riley, Robert Steadman and Aled O Phillips
}

Glucose stimulates proapoptotic signalling pathways in mesangial cells. Studies focused on inflammatory glomerular injury have demonstrated that removal of apoptotic mesangial cells occurs by neighbouring non-apoptotic mesangial cells. The aim of this study was to define the effect of ambient glucose concentration on mesangial handling of apoptotic cells, and in addition to examine the response made by the mesangial cell. We used a co-culture model in which neutrophils aged overnight to induce apoptosis, or apoptotic mesangial cells, labelled with a fluorescent dye, were added to mesangial cells to study phagocytosis. Exposure of mesangial cells to an ambient glucose concentration of $25 \mathrm{mM}$ D-glucose before addition of apoptotic cells led in an increase in mesangial cell phagocytosis. Ingestion of apoptotic cells was inhibited by blocking $\alpha \mathrm{v} \beta 3$ integrin-vitronectin receptor or thrombospondin-1. Furthermore, glucose-dependent stimulation of phagocytosis was inhibited by a blocking antibody to TGF- $\beta 1$. Co-culture of apoptotic cells with mesangial cells stimulated synthesis of TGF- $\beta 1$ as compared to freshly isolated neutrophils. Increased TGF- $\beta 1$ synthesis was dependent on direct contact between the two cell types but was not dependent on phagocytosis of apoptotic cells, as TGF- $\beta 1$ generation was not affected by inhibition of the thrombospondin-1 pathway. We propose a model in which apoptotic cell binding but not phagocytosis stimulates enhanced mesangial cell TGF- $\beta 1$ synthesis. Furthermore phagocytosis, which involves the thrombospondin-1 pathway, is uncoupled from binding of apoptotic cells, which stimulated TGF- $\beta 1$ synthesis.

Laboratory Investigation (2007) 87, 690-701; doi:10.1038/labinvest.3700555; published online 28 May 2007

KEYWORDS: apoptosis; mesangial; phagocytosis; diabetes; TGF- $\beta$; nephropathy

Diabetic nephropathy is a leading cause of end-stage renal disease, which carries high morbidity and mortality rates in patients with diabetes. The early stages of diabetic nephropathy are characterised by thickening of the glomerular basement membrane and glomerular hypertrophy. Increasing mesangial cell number has been documented in the incipient phase of nephropathy, with a direct correlation between mesangial cell number and albumin excretion rates. ${ }^{1}$ This relationship between mesangial cell number is, however, lost in patients with overt nephropathy and proteinuria. In overt nephropathy, expansion of the mesangial matrix, mesangial cell loss and glomerular sclerosis are prominent, associated with proteinuria, hypertension and renal dysfunction., ${ }^{2,3}$ There is clear evidence of a positive relationship between hyperglycaemia and susceptibility to renal disease in diabetes mellitus. Exposure of mesangial cells to conditions of elevated glucose concentration in vitro induces mesangial cells apoptosis. ${ }^{4,5}$ These observations are consistent with loss of mesangial cells through apoptosis, which occurs in experimental diabetic nephropathy. ${ }^{6}$

Apoptosis is considered to be a mechanism by which cells are deleted without damaging surrounding tissues, with clearance occurring by swift recognition and ingestion by phagocytes. Much of the work to date on the recognition mechanisms for apoptotic cells and the consequence of phagocytosis has been studied in macrophages, where engulfment of apoptotic cells is thought not only to remove them from the tissues but also to provide protections from local damage resulting from release or discharge of injurious or proinflammatory content. ${ }^{7}$ Furthermore, recent studies have shown that, in addition to its role in removing cells before they undergo lysis, ingestion of apoptotic cells by macrophages actively suppresses production of proinflammatory cytokines and chemokines. ${ }^{8,9}$ Intriguingly, this suppressive effect was largely inhibited by TGF- $\beta 1$ neutralising antibodies and was reproduced by exogenous

Institute of Nephrology, School of Medicine, Cardiff University, Wales, UK

Correspondence: Professor AO Phillips, MD, Institute of Nephrology, School of Medicine, University of Cardiff, Heath Park, Cardiff CF14 4XN, UK.

E-mail: PhillipsAO@cf.ac.uk 
TGF- $\beta 1$. Apoptotic cell clearance is therefore believed to represent a critical process in tissue remodelling and resolution of inflammatory injury. Within the glomerulus, mesangial cells, which have undergone apoptosis, are predominantly removed by neighbouring non-apoptotic mesangial cells. ${ }^{10}$ Although hyperglycaemia has been implicated in mesangial cell apoptosis, the relationship between hyperglycaemia and mesangial cell handling of apoptotic cells has not been characterised so far. In this study, we have examined the effect of elevated glucose concentration on engulfment of apoptotic cells, and defined the mechanism by which this occurs. In addition, we have examined the functional consequences of interaction between mesangial cells and apoptotic cells with particular emphasis on TGF- $\beta 1$ generation, which has been implicated as a critical factor promoting renal injury in diabetes.

\section{MATERIALS AND METHODS Reagents}

Inhibitors, antibodies and reagents and their sources were as follows: cell culture media, penicillin/streptomycin, L-glutamine, HEPES and hydrocortisone (Life Technologies, Paisley, UK); insulin, transferrin and sodium selenite (Sigma-Aldrich Co. Ltd, Gillingham, UK); fetal bovine serum (Autogen Bioclear UK Ltd, Calne, UK); $\alpha$-smooth muscle actin antibody, desmin antibody and cytokeratin antibody (DakoCytomation, Ely, UK); CFSE (Cambridge Bioscience, Cambridge, UK); recombinant human TGF- $\beta 1$ (R\&D Systems Europe Ltd, Abingdon, UK); pan-specific TGF- $\beta$ antibody (R\&D Systems Europe Ltd); monoclonal anti-human CD18 antibody (Alexis Biochemicals, Nottingham, UK); RGDS and RGES peptides (Sigma-Alrich); thrombospondin1 antibody (R\&D systems); alamar blue (Biosource UK Ltd, Nivelles, Belgium); Bright-Glo ${ }^{\mathrm{TM}}$ luciferase assay reporter system (Promega, Southampton, UK).

\section{Mesangial Cells}

All experiments were performed using spontaneously transformed rat mesangial cell lines. Cells were cultured in a 1:1 ratio of RPMI-1640/Dulbecco's modified Eagle's medium without glucose but supplemented with $10 \%$ fetal bovine serum, insulin, transferrin, sodium selenite, penicillin, streptomycin and L-glutamine. Mesangial cells were characterised on the basis of positive staining for $\alpha$-smooth muscle actin and desmin and negative staining for cytokeratin (data not shown).

\section{Isolation of Neutrophils and Induction of Apoptosis}

Neutrophils were isolated from fresh, citrated blood of healthy volunteers by dextran sedimentation and discontinuous plasma-Percoll density-gradient centrifugation as described previously. ${ }^{10,11}$ Cell number was determined with a Coulter Counter (Beckman Counter). High polymorphic neutrophil (PMN) yield was determined by cytospin preparations. Apoptosis was induced by 'ageing' the neu- trophils. ${ }^{11}$ After isolation, the PMNs were incubated overnight in tissue culture medium containing 10\% FCS at $37^{\circ} \mathrm{C}$. The amount of apoptosis was assessed by FACS analysis using annexin- $\mathrm{V}$ and propidium iodide (PI) staining (Figure 1a), as described previously. ${ }^{12}$ Viable cells were defined as annexin-V/PI negative, cells in early apoptosis were annexin- $\mathrm{V}$ positive and PI negative and cells in late apoptosis/necrosis were annexin-V/PI positive.

\section{FACS Analysis of Phagocytosis}

Isolated neutrophils were labelled with 5,6-carboxyfluorescein diacetate succinimidylester (CFSE), a fluorescent green dye. ${ }^{13}$ The aged PMNs were resuspended in $10 \mathrm{ml}$ of PBS per $30 \times 10^{6}$ PMNs with $20 \mu \mathrm{l}$ of CFSE (stock $5 \mathrm{mM}$ in DMSO). After 10 min incubation in the dark at room temperature, the uptake of the fluorescent cell stain was inhibited by addition of $200 \mu \mathrm{l}$ FCS. The cells were centrifuged (1600 r.p.m., $4^{\circ} \mathrm{C}$ for $7 \mathrm{~min}$ ) and resuspended in $5 \mathrm{mM}$ glucose medium without FCS for co-culture experiments.

For assessment of phagocytosis, labelled neutrophils were co-cultured with mesangial cells for $3 \mathrm{~h}$. The medium was then removed and the PMNs washed off with gentle agitation in PBS, using a Pasteur pipette, three times. A $600 \mu$ l portion of PBS and $100 \mu \mathrm{l}$ of trypsin were then added to each well and the plates were gently agitated, to detach mesangial cells from the plate and to dislodge any bound PMNs. After $10 \mathrm{~min}$, the trypsin was neutralised by adding $100 \mu \mathrm{l}$ of FCS. The cell suspension was then centrifuged at 1600 r.p.m. and $4{ }^{\circ} \mathrm{C}$ for $7 \mathrm{~min}$. The cell pellets were resuspended in PBS and analysed immediately for phagocytosis by flow cytometry.

\section{Generation of Apoptotic Mesangial Cells}

In order to investigate the applicability of our observations to non-immune cells, and specifically to the question of mesangial cell clearance of apoptotic mesangial cells, we sought to validate an experimental model in which an enriched population of apoptotic mesangial cells could be added to normal mesangial cells and phagocytosis quantified. Apoptotic mesangial cells were prepared by incubation at $37^{\circ} \mathrm{C}$ for $48 \mathrm{~h}$ in the presence of $10 \mu \mathrm{M}$ cyclohexamide in supplementfree medium. Subsequently, the percentage of apoptotic mesangial cells was increased by trypsinisation of the cells and allowing the non-apoptotic cells to adhere to a fresh plate overnight.

\section{TGF- $\beta 1$ ELISA}

The mesangial cells were grown to confluence in $5 \mathrm{mM}$ glucose medium, followed by culture in serum-free medium containing 5 or $25 \mathrm{mM}$ glucose for $48 \mathrm{~h}$. Aged neutrophils were then added to the mesangial cells for $3 \mathrm{~h}$. The medium was removed and the PMNs washed off with gentle agitation in PBS, using a Pasteur pipette, three times. Fresh $5 \mathrm{mM}$ glucose medium was added for $48 \mathrm{~h}$ and the concentration of TGF- $\beta 1$ in this medium was then measured. Total TGF- $\beta 1$ in the cell culture supernatant was measured by specific 


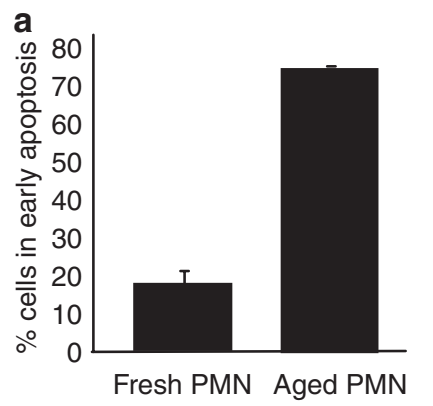

b
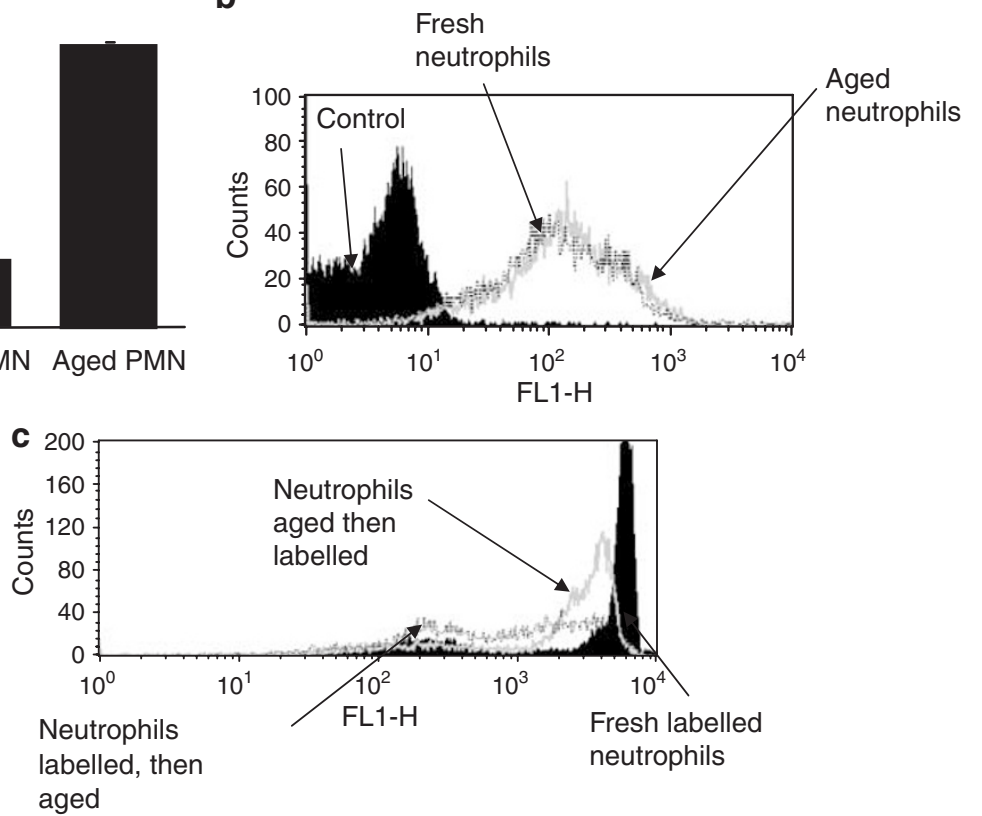

Figure 1 (a) Confirmation of apoptosis of aged PMN. Isolated PMNs were incubated overnight at $37^{\circ} \mathrm{C}$ and the amount of apoptosis was assessed by FACS analysis using annexin- $\mathrm{V}$ as a marker of apoptosis. (b) The degree of cell activation following overnight ageing was assessed by examining cell-surface CD18 expression by FACS analysis in both fresh neutrophils and PMNs aged overnight at $37^{\circ} \mathrm{C}$. (c) Uptake of 5,6-CFSE, a fluorescent green dye, occurs in both fresh and aged PMNs. Fresh cells or cells aged overnight were labelled as described in Materials and methods. In addition, fresh PMNs were labelled and then aged overnight, uptake of fluorescent dye was examined by FACS analysis. enzyme-linked immunosorbent assay (ELISA) (R\&D Systems Europe Ltd) of cell culture supernatant samples collected from growth-arrested mesangial cells, stimulated under serum-free conditions.

\section{TGF- $\beta 1$ Bioactivity}

Activity of TGF- $\beta 1$ was examined by determining the luciferase activity of HK-2 cells transiently transfected with a Smad-responsive promoter construct as we have described previously. ${ }^{14}$ Cells were cultured in a 1:1 ratio of Ham's F12/ Dulbecco's modified Eagle's medium supplemented with $10 \%$ fetal bovine serum, HEPES, L-glutamine, insulin, transferrin, sodium selenite and hydrocortisone. The Smadresponsive promoter $(\mathrm{SBE})_{4}$-Lux was a gift from Aristidis Moustakas (Ludwig Institute for Cancer Research, Uppsala, Sweden). ${ }^{15}$ Conditioned medium was generated by culturing mesangial cells under serum-free conditions in either 5 or $25 \mathrm{mM}$ D-glucose for $48 \mathrm{~h}$, before addition of apoptotic cells for a further $3 \mathrm{~h}$. Subsequently, the medium containing PMNs was removed and replaced with serum-free medium for a further $48 \mathrm{~h}$ before collection of the culture medium. Subsequently, conditioned medium was added to cells transfected with the Smad reporter construct $24 \mathrm{~h}$ before determining luciferase activity.

\section{Statistical Analysis}

Statistical analysis was performed using the unpaired Student's $t$-test, with a value of $P<0.05$ considered to represent a significant difference. The data are presented as means \pm s.d. of $n$ experiments as indicated in the figure legends. For each individual experiment, the mean of duplicate determinations was calculated.

\section{RESULTS}

\section{Confirmation of Induction of PMN Apoptosis}

Using annexin-V positivity as a marker of apoptosis, FACS analysis confirmed apoptosis in greater than 70\% of PMNs following overnight ageing. PI positivity was not significantly different between fresh isolated neutrophils and aged neutrophils $(6.17 \pm 3.3$ vs $10.29 \pm 5.8 \%)$, thus excluding significant neutrophil necrosis during generation of apoptotic cells. In order to assess the impact of isolation and overnight ageing on neutrophil activation, cell-surface expression of CD18 in fresh isolated with aged neutrophils was assessed by flow cytometry. Fresh and aged PMNs were incubated in FACS buffer (500 ml PBS, $10 \mathrm{mM}$ EDTA, $15 \mathrm{mM}$ sodiumazide, 1\% BSA, pH 7.35) with the primary mouse anti-CD18 antibody (1:1000 dilution, diluted in FACS buffer) for $30 \mathrm{~min}$ at $4^{\circ} \mathrm{C}$. The cells were washed in PBS and incubated with anti-mouse-fluorescein isothiocyanate (FITC)-conjugated antibody (1:100 dilution) for $30 \mathrm{~min}$ at $4{ }^{\circ} \mathrm{C}$ before analysis by flow cytometry (Figure 1b). These data suggest that the method is not in association with significant cell activation, as CD18 expression in the freshly isolated neutrophils was identical to its expression in the aged cells. Uptake of fluorescent dye following in vitro ageing was confirmed by FACS analysis (Figure 1c). In contrast, if cells were labelled before in vitro ageing, fluorescence intensity was markedly reduced.

\section{Demonstration of Ingestion of Apoptotic PMN by Mesangial Cells}

Following labelling of apoptotic neutrophils and co-culture with mesangial cells, uptake of fluorescent apoptotic neutrophils was assessed by flow cytometry. The $x$-axis was set up to measure cell size (mesangial cells are larger than PMNs) and 
the $y$-axis was set up to measure green fluorescence (only PMNs labelled, therefore any 'labelled' mesangial cells have ingested PMNs) (Figure 2a). One issue with flow cytometric assay is the possibility of detection of cell association. In order to exclude this possibility, we compared expression of annexin- $\mathrm{V}$ in aged neutrophils, mesangial cells and mesangial cells co-cultured with aged neutrophils following light trypsin treatment as described above. As expected, annexin- $\mathrm{V}$ was highly expressed in the aged neutrophils compared to mesangial cells. Following co-culture and trypsin treatment by FACS analysis, expression of annexin- $\mathrm{V}$ in co-cultured mesangial cells and aged neutrophils was similar to that of mesangial cells alone (Figure 2b). These data therefore suggest that no cell association occurs following trypsin treatment of co-cultured cells.

In order to assess the impact of isolation of PMNmesangial cell co-culture on PMN activation, surface expression of CD18 in freshly isolated and aged apoptotic neutrophils co-cultured with mesangial cells was assessed by flow cytometry. No increase in CD18 expression was seen following co-culture of either fresh PMN or apoptotic PMN with mesangial cells (Figure 2c). Although PMA stimulation of freshly isolated PMA led to increased CD18 expression, stimulation of apoptotic PMN did not alter CD18 expression compared to un stimulated apoptotic PMN, not apoptotic PMN co-cultured with mesangial cells. The data therefore suggest that co-culture of apoptotic PMN does not lead to its activation.

\section{Uptake of Apoptotic Mesangial Cells by Healthy Mesangial Cells}

Following the protocol outlined above, and using annexin- $\mathrm{V}$ positivity as a marker of apoptosis, FACS analysis confirmed apoptosis of $80 \%$ of the non-adherent mesangial cells (Figure $3 a)$. These were used in the subsequent 'phagocytosis' experiments. Apoptotic mesangial cells were labelled with CFSE, as described above, and uptake of fluorescent dye was confirmed by FACS analysis (Figure 3b). For assessment of phagocytosis, labelled apoptotic mesangial cells were cocultured with normal mesangial cells for $3 \mathrm{~h}$. The medium was then removed and the non-internalised apoptotic mesangial cells were washed off with gentle agitation. A $600 \mu \mathrm{l}$ portion of PBS and $100 \mu \mathrm{l}$ of trypsin were then added to each well and the plates were gently agitated, to detach the mesangial cells, and phagocytosis was assessed as described above (Figure $3 \mathrm{c}-\mathrm{e}$ ). Internalisation of apoptotic mesangial cells was also confirmed by cytospin analysis. Mesangial cells that had been co-cultured as described were cytospin onto glass slides and examined by microscopy. Small apoptotic cells were visible inside some of the healthy phagocytic mesangial cells, and on examination under fluorescence, these internalised apoptotic cells were shown to fluoresce, demonstrating the uptake of the CFSE-labelled cells (Figure 3e, inset).

\section{Mesangial Cell Uptake of Apoptotic Cells}

Quantification of phagocytosis of apoptotic PMNs by flow cytometry and immunofluorescence confirmed a dosedependent effect of FCS on their uptake (Figure 4a). Using the phagocytosis assay, pretreatment of confluent mesangial cells with $25 \mathrm{mM}$ D-glucose for $48 \mathrm{~h}$ before the addition of apoptotic PMNs led to a significant increase in CFSE-positive mesangial cells compared to pretreatment with $5 \mathrm{mM}$ D-glucose for the same time period, indicating greater uptake of apoptotic PMNs by mesangial cells exposed to high glucose concentrations (Figure $4 \mathrm{~b}$ ).

\section{TGF- $\beta 1$ Pretreatment Increased Mesangial Cell Uptake of Apoptotic Cells}

Addition of recombinant TGF- $\beta 1$ to confluent monolayers of mesangial cells for $48 \mathrm{~h}$ under serum-free conditions before addition of apoptotic PMNs mimicked the effect of $25 \mathrm{mM}$ D-glucose and led to a significant increase in CFSE-positive mesangial cells at all concentrations of TGF- $\beta 1$ that we used. Furthermore, addition of a neutralising antibody to TGF- $\beta 1$ together with $25 \mathrm{mM}$ D-glucose for $48 \mathrm{~h}$ before addition of apoptotic PMNs significantly decreased $25 \mathrm{mM}$ D-glucosedependent stimulation of apoptotic PMN engulfment (Figure 5).

\section{Mechanism of Engulfment}

Previous reports suggest that binding and ingestion of apoptotic cells by mesangial cells may involve the vitronectin receptor/thrombospondin-1-dependent pathway. ${ }^{11}$ Mesangial cells were grown to confluence before addition of $25 \mathrm{mM}$ D-glucose for $48 \mathrm{~h}$. Subsequently, apoptotic PMNs were added in the presence of the RGDS tetrapeptide, an antagonist to the thrombospondin-1-bridged vitronectin integrin recognition mechanism. RGDS significantly inhibited phagocytosis of apoptotic PMNs when added together with apoptotic cells when mesangial cells were pretreated with either 5 or $25 \mathrm{mM}$ D-glucose (Figure 6). Addition of a control RGES peptide had no effect on phagocytosis. Addition of monoclonal antibody to 'bridging' thrombospondin-1 also prevented phagocytosis of apoptotic PMNs by mesangial cells (Figure 6).

\section{Phagocytosis of Mesangial Cells}

Pretreatment of confluent mesangial cells with $25 \mathrm{mM} \mathrm{D-}$ glucose for $48 \mathrm{~h}$ before the addition of CFSE-labelled apoptotic mesangial cells led to a significant increase in CFSEpositive phagocytic mesangial cells compared to pretreatment with $5 \mathrm{mM} \mathrm{D}$-glucose for the same time period, suggesting greater uptake of apoptotic mesangial cells by healthy mesangial cells exposed to high glucose concentrations (Figure 7a). As with apoptotic neutrophils, addition of apoptotic mesangial cells in the presence of the RGDS tetrapeptide significantly inhibited phagocytosis of the apoptotic mesangial cells (Figure 7b). 
a

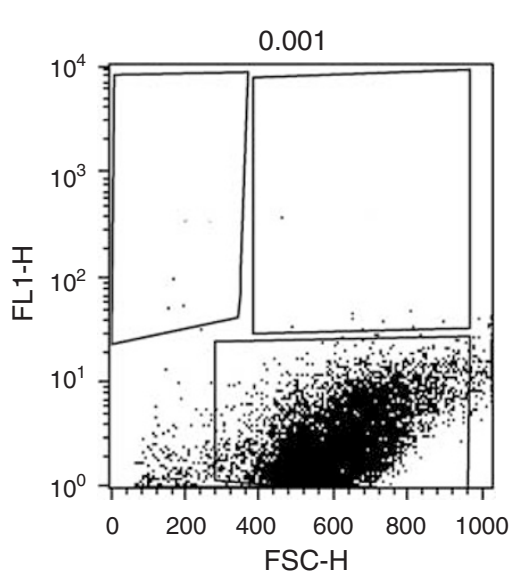

PMN alone

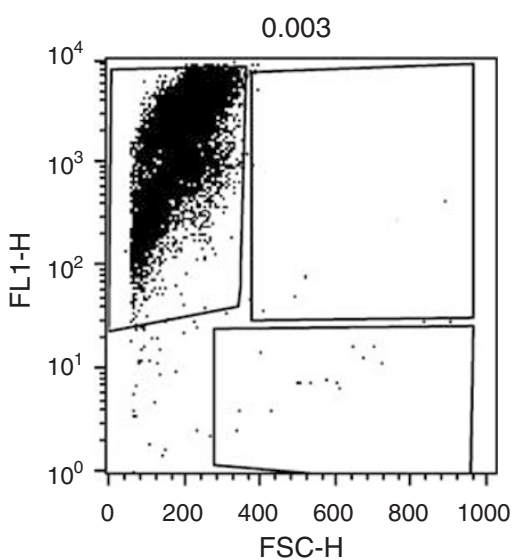

Mesangial cells with ingested PMN

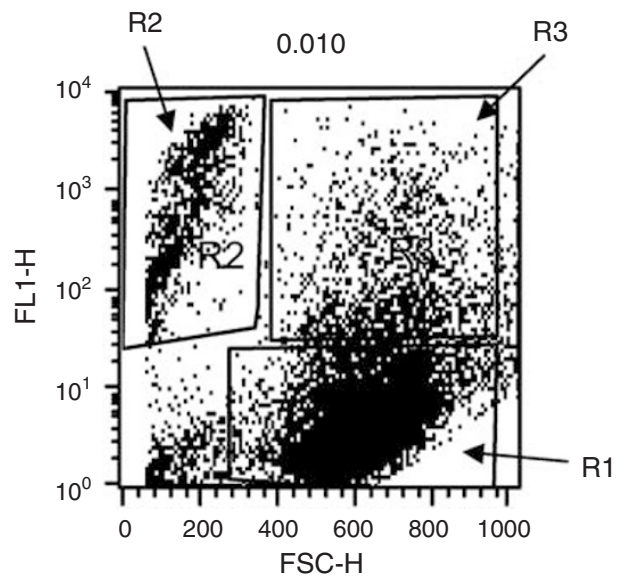

b

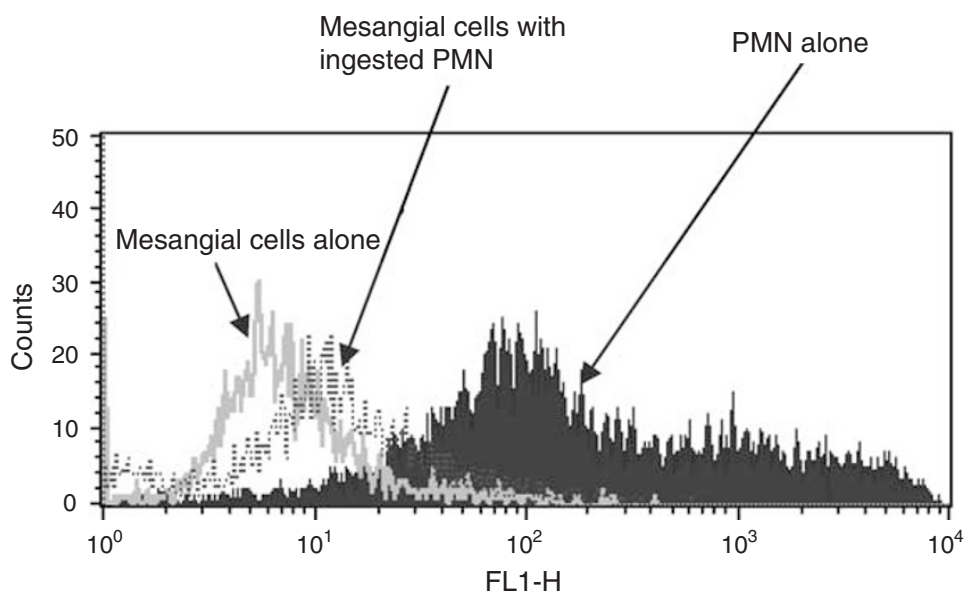

C

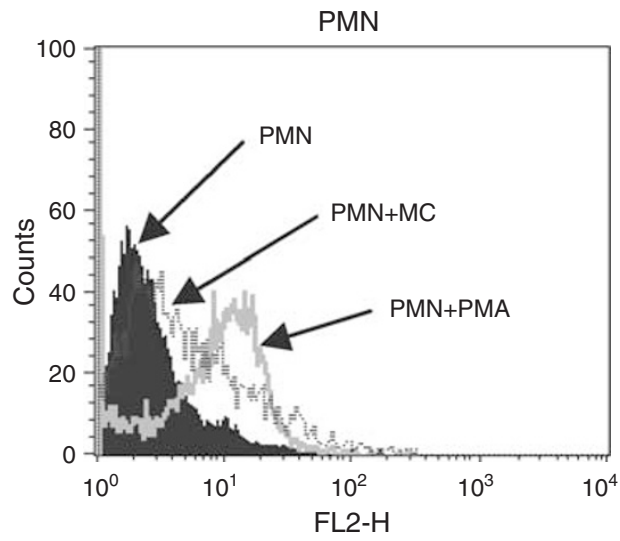

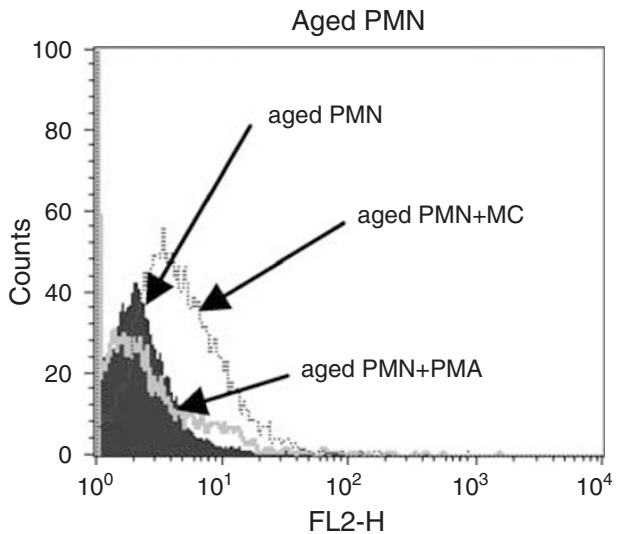

Figure 2 (a) Ingestion of labelled, aged PMNs by mesangial cells determined by FACS. The $x$-axis was set up to measure cell size (mesangial cells are larger than PMNs) and the $y$-axis was set up to measure green fluorescence. Representative FACS profiles of unlabelled mesangial cells, CFSE-labelled aged PMNs and mesangial cells co-cultured with CFSE-labelled PMNs are shown. In the co-cultured system, applying the gate parameter from the mesangial cells alone or PMN alone allows distinction between mesangial cells (R1), aged uningested PMNs (R2) and ingested apoptotic PMNs (R3). (b) Trypsin treatment prevents cell association when aged PMNs are co-cultured with mesangial cells. Annexin-V expression was assessed by FACS in aged PMNs, mesangial cells and mesangial cells co-cultured with aged PMNs. Following $3 \mathrm{~h}$ co-cultures, $600 \mu \mathrm{l}$ of PBS and $100 \mu \mathrm{l}$ of trypsin were added to each well and the plates were gently agitated to detach the mesangial cells from the plate and to dislodge any bound PMNs. After 10 min, the trypsin was neutralised by adding $100 \mu$ l of FCS. The cell suspension was then centrifuged at 1600 r.p.m. and $4^{\circ} \mathrm{C}$ for 7 min. The cell pellets were resuspended in PBS and analysed for annexin-V immediately by flow cytometry. (c) Influence of co-culture on PMN activation. Mesangial cells (MC) at $70 \%$ confluence were growth arrested in the absence of serum for $48 \mathrm{~h}$. PMN freshly isolated from peripheral blood (PMN) or apoptotic PMN (aged PMN) were then added at a concentration of $2 \times 10^{6} / \mathrm{ml}$ for $3 \mathrm{~h}$ in the presence of $10 \%$ FCS. Non-attached PMN were then removed by gentle washing $(\times 3)$ with PBS and the incubation allowed to continue for a further $48 \mathrm{~h}$ in the absence of serum. Control fresh or aged PMN were either incubated alone for $48 \mathrm{~h}$ or stimulated with PMA (10 nM). Following $48 \mathrm{~h}$ incubation, the cells were harvested with trypsin/EDTA, washed, and CD18 expression detected by FACS analysis as a marker of PMN activation. 


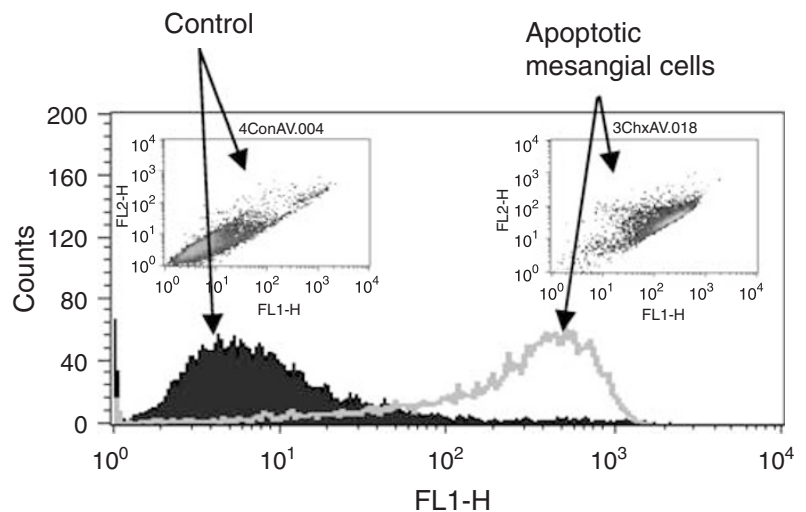

b

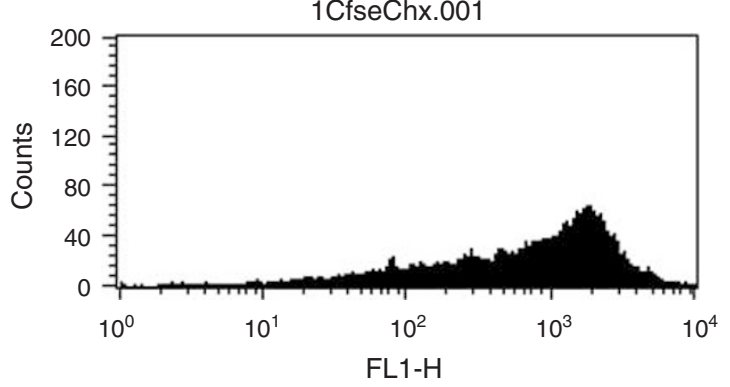

C

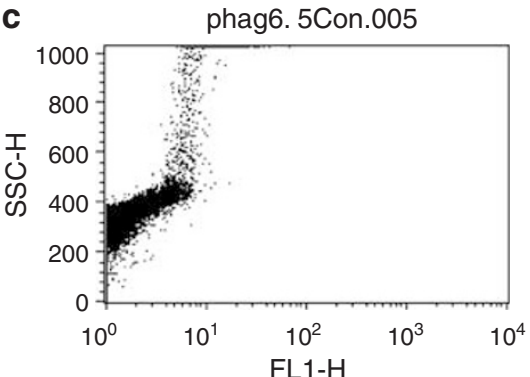

d

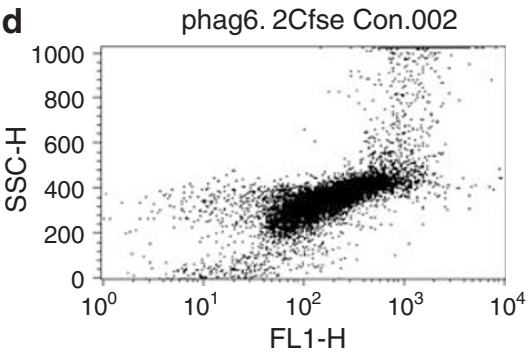

e

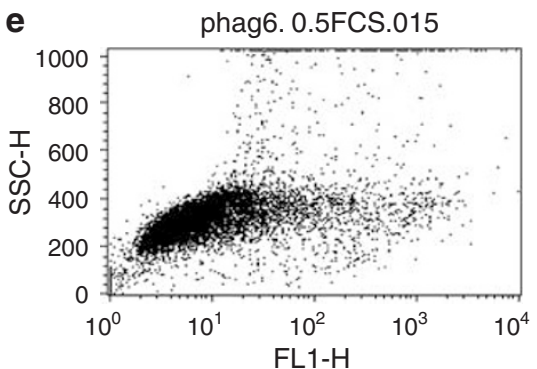

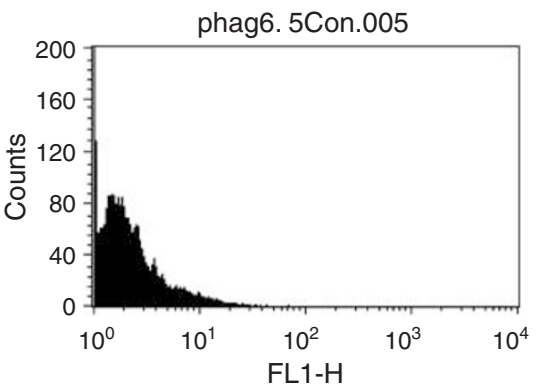
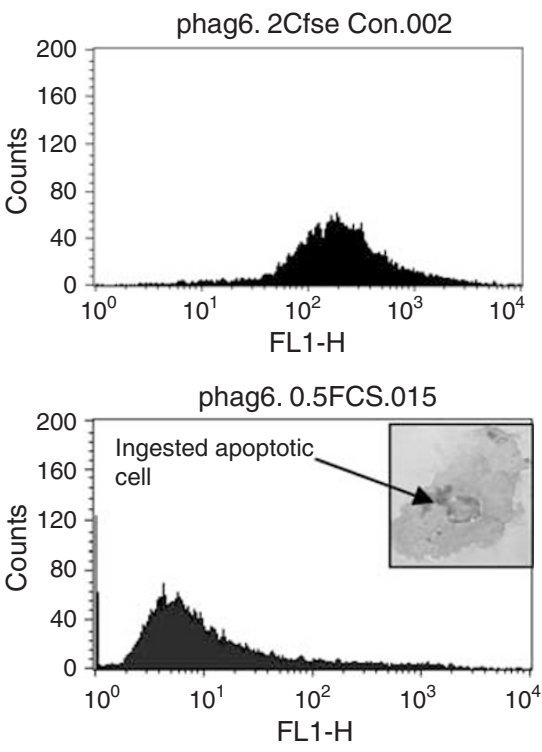

Figure 3 Induction of apoptosis and phagocytosis of apoptotic mesangial cells. Apoptotic mesangial cells were generated by incubation at $37^{\circ} \mathrm{C}$ for $48 \mathrm{~h}$ in the presence of $10 \mu \mathrm{M}$ cyclohexamide. Cells were then trypsinised and added to fresh culture plates and incubated overnight again at $37^{\circ} \mathrm{C}$. Subsequently, nonadherent cells were collected and apoptosis assessed by FACS analysis using annexin-V as a marker of apoptosis (a). In addition, FACS analysis using annexin-V conjugated to FITC, in conjunction with $\mathrm{Pl}$, was used to distinguish apoptotic cells (annexin-V-FITC positive, PI negative) from necrotic cells (annexin-V-FITC positive, PI positive) (a, insets). Uptake of 5,6-CFSE by apoptotic mesangial cells was confirmed by FACS analysis (b). Ingestion of labelled apoptotic mesangial cells determined by FACS. Representative FACS profiles of unlabelled mesangial cells (c), CFSE-labelled apoptotic mesangial cells (d) and mesangial cells co-cultured with CFSE-labelled apoptotic mesangial cells (e) are shown. In the left-hand panels, the $x$-axis was set up to measure cell size and the $y$-axis green fluorescence; in the right-hand panel, the $x$-axis was set up to measure cell number and the $y$-axis green fluorescence. Internalisation of apoptotic mesangial cells was also confirmed by cytospin analysis and fluorescent microscopy (e, inset). 


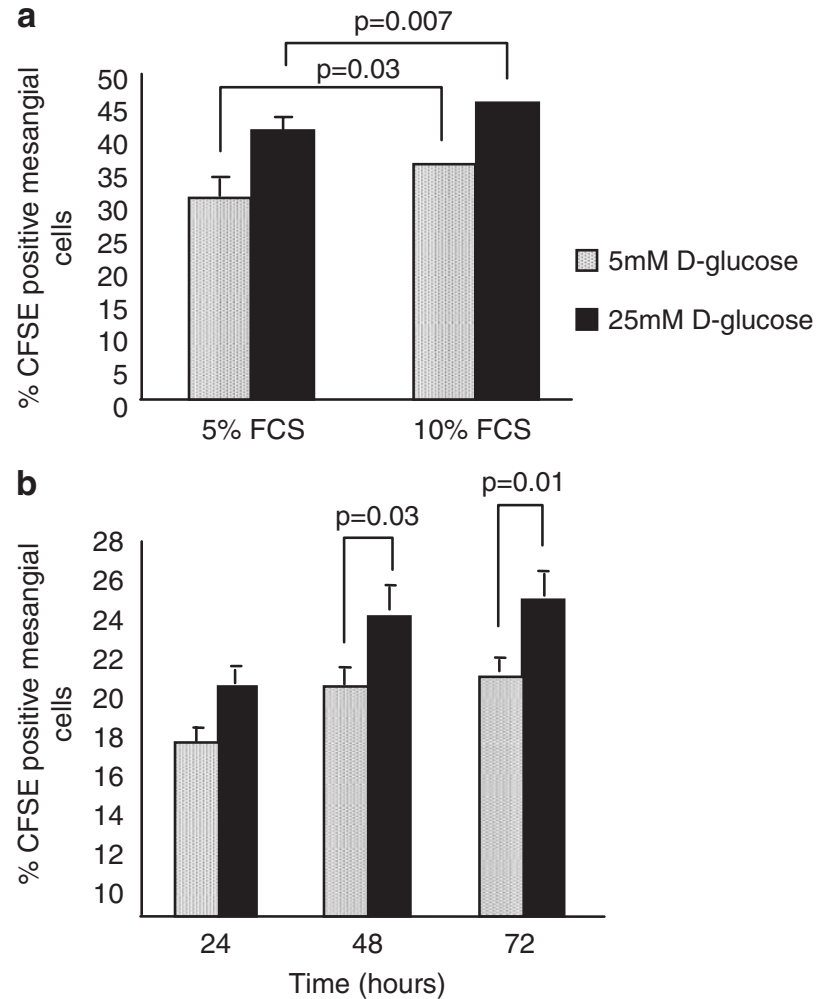

Figure 4 Phagocytosis of apoptotic cells is dependent on the presence of FCS and is increased under conditions of high ambient glucose concentration. (a) Quantitation of phagocytosis by flow cytometry. CFSElabelled PMNs were added for $3 \mathrm{~h}$ to mesangial cells pretreated with either $5 \mathrm{mM}$ (stippled bars) or $25 \mathrm{mM}$ D-glucose (solid bars) for $48 \mathrm{~h}$. Co-culture of aged PMNs and mesangial cells was carried out in the presence of FCS added at concentrations indicated. Phagocytosis was examined by flow cytometry and the results expressed as a percentage of the total number of mesangial cells. Data represent mean \pm s.e.m., $n=3$. (b) Time-dependent effect of glucose pretreatment on phagocytosis. Mesangial cells were cultured under serum-free conditions with an ambient D-glucose concentration of $5 \mathrm{mM}$ (stippled bars) or $25 \mathrm{mM}$ (solid bars) for 24-72 $\mathrm{h}$ before co-culture with aged CFSE-labelled PMNs in the presence of $10 \%$ FCS for a further $3 \mathrm{~h}$. Phagocytosis of labelled PMNs was subsequently determined by FACS. The results are expressed as the percentage of CFSE-positive mesangial cells in the sampled population. Data represent mean \pm s.e.m., $n=3$.

\section{TGF- $\beta 1$ Synthesis by Mesangial Cells during Co-Culture with Apoptotic Cells}

As shown in Figure 8, mesangial cells co-cultured with apoptotic PMNs for $3 \mathrm{~h}$ produced significantly more TGF- $\beta 1$ as compared to mesangial cells cultured alone or co-cultured with fresh PMNs. Pretreatment of confluent mesangial cells with $25 \mathrm{mM}$ D-glucose had no further stimulatory effect on TGF- $\beta 1$ generation following addition of either apoptotic or fresh PMNs compared to pretreatment with $5 \mathrm{mM}$ D-glucose. Medium collected from freshly isolated PMNs incubated in tissue culture medium for $3 \mathrm{~h}$, from PMNs following overnight 'ageing' or medium collected following incubation of aged PMN for $3 \mathrm{~h}$ in tissue culture medium all contained less

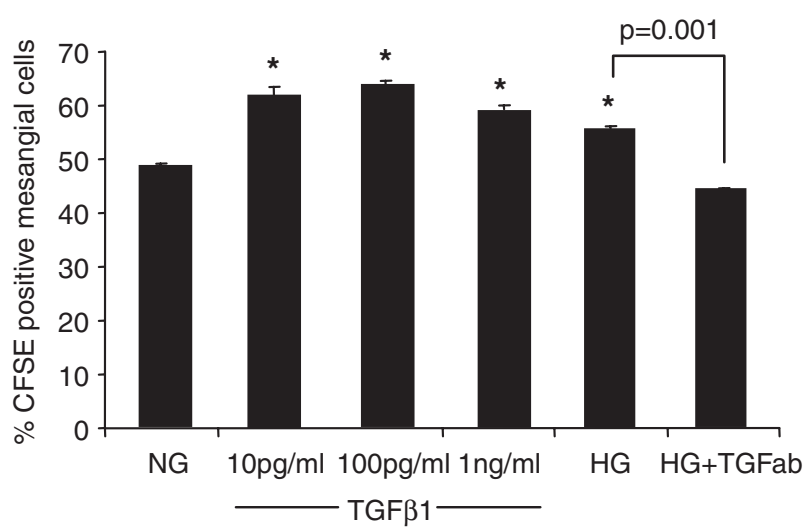

Figure 5 TGF- $\beta 1$ stimulates phagocytosis of aged neutrophils. Mesangial cells were cultured under serum-free conditions either in the presence of $5 \mathrm{mM}$ alone (NG) or together with recombinant TGF- $\beta 1$ at the concentrations shown for $48 \mathrm{~h}$. Subsequently, aged CFSE-labelled PMNs were added for a further $3 \mathrm{~h}$ in the presence of $10 \% \mathrm{FCS}$. The effect of inhibition of TGF- $\beta 1$ on glucose-stimulated phagocytosis was examined in parallel experiments; mesangial cells were cultured under serum-free conditions in the presence of $25 \mathrm{mM}$ D-glucose alone (HG) or together with $20 \mu \mathrm{g} / \mathrm{ml}$ of blocking antibody to TGF- $\beta 1$ (HG + TGFab) for $48 \mathrm{~h}$ before addition of CFSE-labelled PMNs in the presence of $10 \%$ FCS. Data represent mean \pm s.e.m. \%CFSE-positive mesangial cells, $n=3,{ }^{*} P<0.01$ compared to NG.

than $200 \mathrm{pg} / \mathrm{ml}$ of TGF- $\beta 1$, suggesting that PMNs were not the source of TGF- $\beta 1$.

TGF- $\beta 1$ is generated in a latent form that may be activated by proteolytic processing of the latent complex, ${ }^{16,17}$ and also by conformation change of the latent complex, which may be mediated by integrin binding. ${ }^{18}$ Biological activity of TGF- $\beta 1$ in the cell culture supernatant following co-culture of mesangial cells with apoptotic PMNs was assessed by determining the luciferase activity of HK-2 cells transiently transfected with a Smad-responsive promoter construct as we have described previously. ${ }^{14}$ Mesangial cells were pretreated with 5 or $25 \mathrm{mM} \mathrm{D}$-glucose for $48 \mathrm{~h}$ before addition of apoptotic PMNs for a further $3 \mathrm{~h}$. Subsequently, PMNs were removed and after a further $48 \mathrm{~h}$ incubation in serum-free medium, the culture medium was collected and added to HK-2 cells transfected with the Smad-responsive reporter construct and luciferase activity was determined. In control experiments, media were collected from mesangial cells cultured in either 5 or $25 \mathrm{mM} \mathrm{D}$-glucose without apoptotic PMNs. In addition, to exclude TGF- $\beta 1$ activity by apoptotic PMNs, the activity of media collected following overnight ageing of PMNs was quantified. Conditioned medium collected from mesangial cells co-cultured with apoptotic PMNs induced a significant increase in luciferase activity of the promoter construct compared to the controls, confirming that TGF- $\beta 1$ was generated in its active form (Figure 9). There was no difference in TGF- $\beta 1$ activity of the co-culture medium collected from mesangial cells pretreated with 5 or $25 \mathrm{mM}$ D-glucose. 


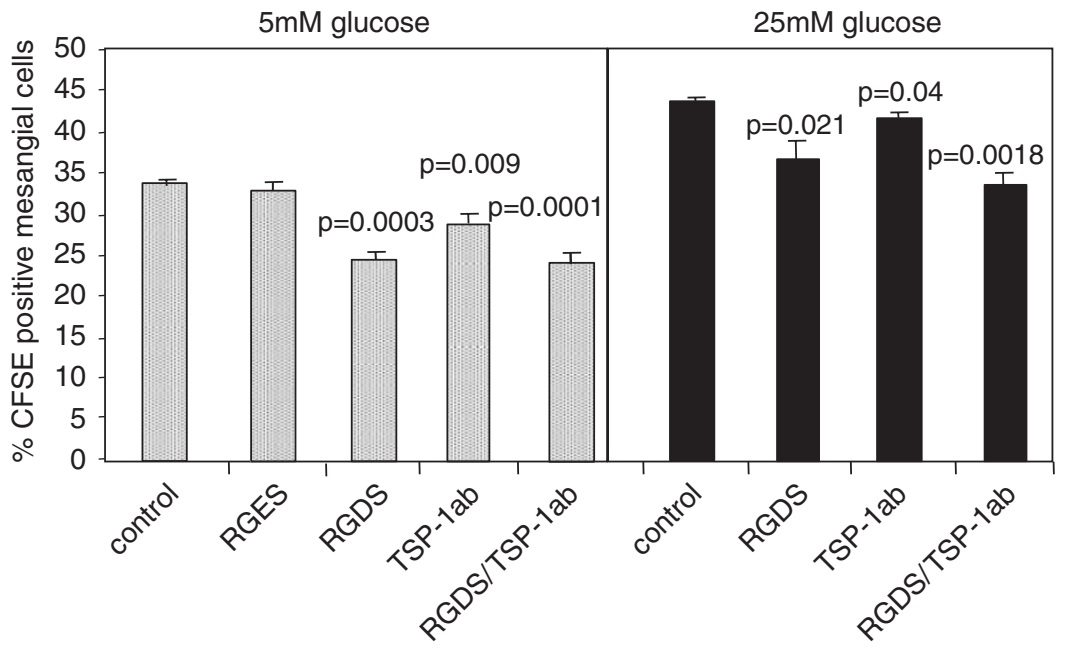

Figure 6 Phagocytosis is dependent on the $\alpha v \beta 3 /$ thrombospond-1 recognition pathway. Mesangial cells were cultured in the presence of 5 or $25 \mathrm{mM}$ D-glucose but in the absence of serum as indicated for $48 \mathrm{~h}$. Subsequently, aged CFSE-labelled PMNs (in 10\% FCS) were added for a further $3 \mathrm{~h}$ either alone (control) or in the presence of RGDS $(100 \mu \mathrm{M})$, RGES $(100 \mu \mathrm{M})$, anti-thrombospondin-1 antibody $(7 \mu \mathrm{g} / \mathrm{ml})$ or a combination of both. Phagocytosis was subsequently determined by quantitation of the \%CFSE-positive mesangial cells by FACS. Data represent mean \pm s.e.m., $n=3$.
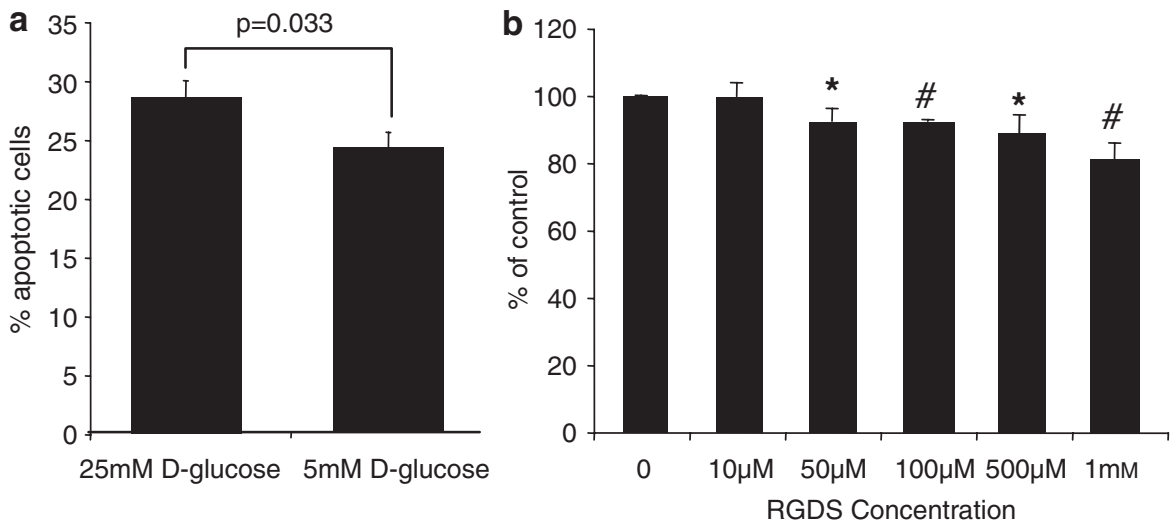

Figure 7 Glucose enhances phagocytosis of apoptotic mesangial cells (a). Mesangial cells were cultured under serum-free conditions with an ambient D-glucose concentration of 25 or $5 \mathrm{mM}$ for $48 \mathrm{~h}$ before co-culture with CFSElabelled apoptotic mesangial cells in the presence of $10 \%$ FCS for a further $3 \mathrm{~h}$. Phagocytosis of labelled mesangial cells was subsequently determined by FACS. The results are expressed as the percentage of CFSE-positive mesangial cells in the sampled population. Data represent mean \pm s.e.m., $n=3$. Phagocytosis of apoptotic mesangial cells is dependent on the $\alpha v \beta 3 /$ thrombospond-1 recognition pathway (b). Mesangial cells were cultured in the presence of $5 \mathrm{mM}$ but in the absence of serum for $48 \mathrm{~h}$. Subsequently, CFSE-labelled apoptotic mesangial cells (in 10\% FCS) were added for a further $3 \mathrm{~h}$ in the presence of increasing concentrations of RGDS. Phagocytosis was subsequently determined by quantitation of the $\%$ CFSE-positive mesangial cells by FACS. Data represent mean \pm s.e.m., $n=6 .{ }^{\star} P<0.05$, ${ }^{\#} P<0.005$ compared to control.

\section{TGF- $\beta 1$ Synthesis is not Dependent on Internalisation but is Dependent on Binding}

To judge whether enhanced TGF- $\beta 1$ synthesis was dependent on ingestion of apoptotic cells, mesangial cells and apoptotic PMNs were co-cultured for $3 \mathrm{~h}$ in the presence or absence of $10 \%$ FCS, as internalisation is known to be FCS dependent. Subsequently, the medium was removed and replaced with serum-free medium for a further $48 \mathrm{~h}$ before quantitation of TGF- $\beta 1$. There was no significant difference in the production of TGF- $\beta 1$ when apoptotic PMNs were added to mesangial cells either in the presence or absence of $10 \%$ FCS (Figure 10a). This suggests that TGF- $\beta 1$ production occurs independently from internalisation of apoptotic cells. This is further supported by the lack of effect on mesangial cell TGF$\beta 1$ generation of either RGDS or monoclonal anti-throm- bospondin-1 antibody, when added together with apoptotic PMNs (Figure 10b).

To determine whether the increase in TGF- $\beta 1$ expression was the result of the release of soluble factors from the apoptotic cells or a result of interaction between the two cell types, two different assays were employed. The effect of apoptotic PMNs on mesangial cell-generated TGF- $\beta 1$ was assessed by co-culture experiments in which the two cell types were separated by a permeable tissue culture insert (pore size $1.0 \mu \mathrm{m}$ ), and by medium transfer assays. When mesangial cells were grown to confluence on 24-well plates and apoptotic PMNs added to the apical aspect of a tissue culture insert, thus allowing co-culture in the absence of direct cell-cell contact, there was no significant increase in luciferase activity relative to the control value in which 


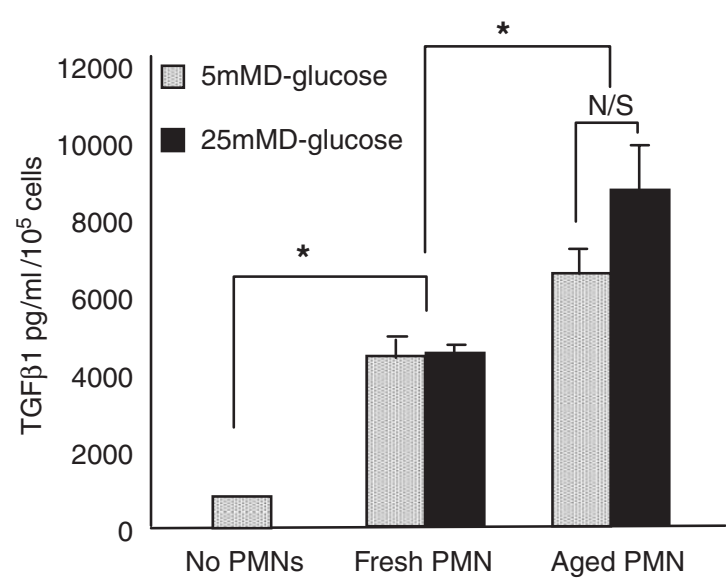

Figure 8 Co-culture of aged PMN with mesangial cells stimulates TGF- $\beta 1$ generation. Mesangial cells were cultured in the presence of either $5 \mathrm{mM}$ (stippled bars) or $25 \mathrm{mM}$ (solid bars) D-glucose for $48 \mathrm{~h}$. Subsequently, following aspiration of the culture medium, either freshly isolated or aged PMNs were added for a further $3 \mathrm{~h}$ in the presence of $10 \%$ FCS. At the end of the $3 \mathrm{~h}$ co-culture period, the medium containing PMNs was removed and replaced with serum-free medium for a further $48 \mathrm{~h}$ before quantitation of TGF- $\beta 1$ concentration in the supernatant by ELISA. In control experiments, TGF- $\beta 1$ was quantified in the supernatant taken from mesangial cells treated in an identical manner with the omission of aged PMNs. Data represent mean \pm s.e.m., $n=3,{ }^{*} P<0.05$.

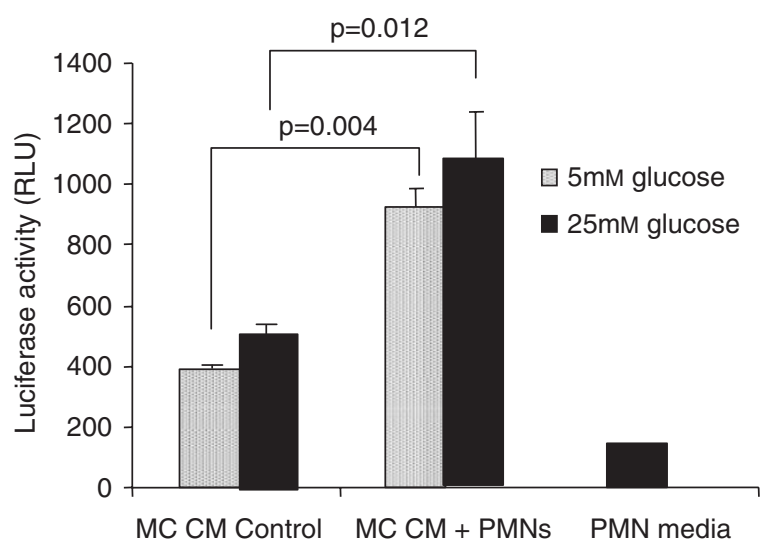

Figure 9 Co-culture of aged PMNs with mesangial cells stimulates the generation of bioactive TGF- $\beta 1$. Mesangial cells were pretreated with $5 \mathrm{mM}$ (stippled bars) or $25 \mathrm{mM}$ (solid bars) D-glucose for $48 \mathrm{~h}$ before addition of apoptotic cells for a further $3 \mathrm{~h}$. Subsequently, the medium containing PMNs was removed and replaced with serum-free medium for a further $48 \mathrm{~h}$ before collection of the culture medium (MC CM + PMNs) and determination of the biological activity of TGF- $\beta 1$ by its addition to HK-2 cells transfected with the Smad-responsive luciferase-reporter construct. In control experiments, TGF- $\beta 1$ was quantified in the supernatant taken from mesangial cells treated in an identical manner with the omission of aged PMNs (MC CM Control). In addition, to exclude TGF- $\beta 1$ activity by apoptotic cells, the activity of media collected following overnight ageing of PMNs was quantified. In all experiments, luciferase activity was quantified $24 \mathrm{~h}$ after the addition of conditioned medium to the transfected HK-2 cells. Results represent means \pm s.e.m. of three individual experiments.

mesangial cells were cultured in the absence of apoptotic PMNs (Figure 11a). In contrast, there was a significant increase in TGF- $\beta 1$ production when apoptotic PMNs were added directly onto the mesangial cells below the insert. Similarly, addition of apoptotic PMN-conditioned medium to mesangial cell did not result in a significant increase in TGF- $\beta 1$ production over the control value (Figure 11b).

\section{DISCUSSION}

Changes in glomerular cell number are an important component of the alterations in glomerular structure associated with development of diabetic nephropathy. Numerous studies have demonstrated that an increase in the ambient glucose concentration to which mesangial cells are exposed directly affects many mesangial cell functions. ${ }^{19-24}$ Landmark studies of Wolf $e t a^{20}$ demonstrated a biphasic growth response of mesangial cells when they were cultured in high glucose concentration. Initially, there was a transient stimulation of replication for $24-48 \mathrm{~h}$ followed by a sustained inhibition after longer incubation. ${ }^{20}$ Furthermore, these studies demonstrated that this inhibitory effect was mediated by glucose-induced synthesis of TGF- $\beta 1$. In addition to regulating mesangial cell proliferation, elevated glucose concentration also stimulates mesangial cell apoptosis. ${ }^{4,5}$ It is accepted that mesangial cells are 'semi-professional' phagocytes, which recognise and ingest apoptotic leucocytes in inflamed glomeruli and that this is an important mechanism that governs resolution of glomerular inflammation. ${ }^{25}$ In addition to the removal of inflammatory cells, apoptosis is also responsible for the deletion of excess mesangial cells as the glomerulus recovers from injury. ${ }^{25}$ During this process, mesangial cells, that have undergone apoptosis are predominantly removed by neighbouring non-apoptotic mesangial cells. In macrophages, two major recognition pathways have been characterised for phagocytosis of apoptotic PMNs. Phosphatidylserine receptors (PSR) on macrophages can bind to phosphatidylserine exposed on apoptotic cells by loss of membrane asymmetry. ${ }^{26}$ In addition, the macrophage $\alpha \mathrm{v} \beta 3$ integrin vitronectin receptor cooperates with CD36 to bind thrombospondin-1, which bridges the macrophage to unknown moieties on the apoptotic cell surface. ${ }^{27,28}$ Similar mechanisms have also been proposed for mesangial cell recognition of apoptotic cells, as binding but not phagocytosis of apoptotic cells may be prevented by inhibition of the PSR, ${ }^{29}$ whereas the $\alpha \mathrm{v} \beta 3$ vitronectin/ thrombospondin-1 mechanism has been implicated in the phagocytosis and ingestion of apoptotic neutrophils. ${ }^{11}$

The data demonstrate that mesangial cell pretreatment with $25 \mathrm{mM}$ D-glucose leads to greater ingestion of apoptotic cells. As with previous studies, ingestion of apoptotic cells is dependent on the presence of serum. ${ }^{13}$ Furthermore, glucoseenhanced phagocytosis was TGF- $\beta 1$ dependent. TGF- $\beta 1$ is a well-established mediator of fibrotic changes associated with diabetic nephropathy in both the glomerulus and interstitium. Glucose-stimulated mesangial cell synthesis and secretion of bioactive TGF- $\beta 1$ has been well documented. ${ }^{30-32}$ In addition, glucose has been demonstrated to enhance sensitivity to the effects of TGF- $\beta 1 .^{33}$ Both mechanisms may 

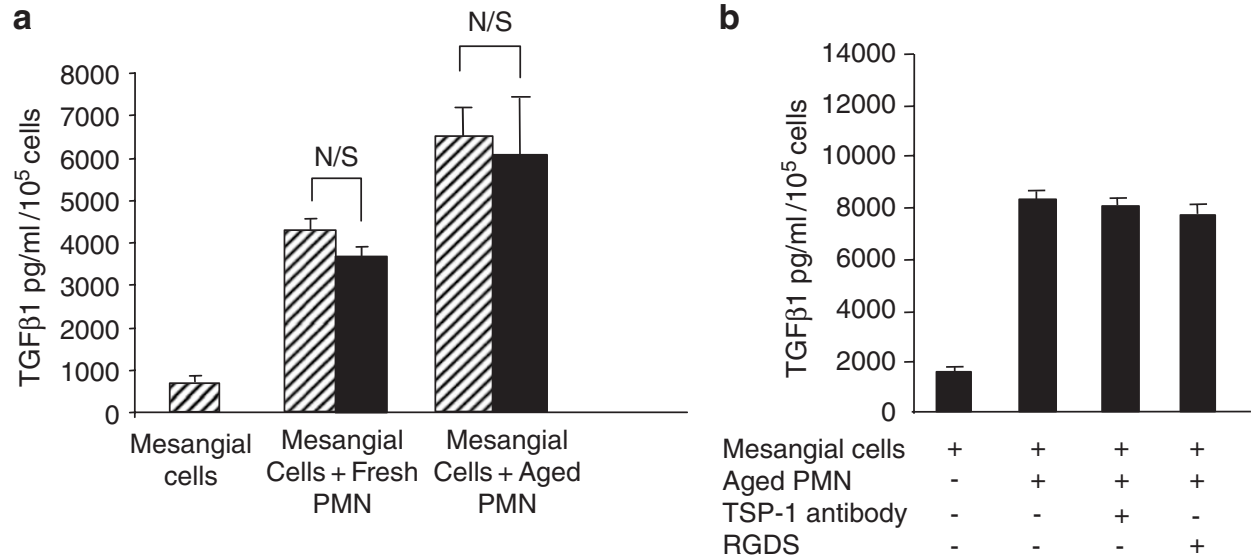

Figure 10 TGF- $\beta 1$ generation is stimulated independently of ingestion of apoptotic cells. Mesangial cells were grown under serum-free conditions (D-glucose concentration $5 \mathrm{mM}$ ) for $48 \mathrm{~h}$. Subsequently, either freshly isolated or aged PMNs were added as indicated for a further $3 \mathrm{~h}$ either in the absence (cross-hatched bars) or presence (solid bars) of 10\% FCS. After $3 \mathrm{~h}$ of co-culture, the medium containing PMNs was removed and replaced with serum-free medium for a further $48 \mathrm{~h}$ before quantitation of TGF- $\beta 1$ in the supernatant by ELISA (a). In control experiments, TGF- $\beta 1$ was quantified in the supernatant taken from mesangial cells exposed to serum-free medium only for $48 \mathrm{~h}$. Data represent mean \pm s.e.m., $n=3$. Inhibition of phagocytosis did not influence TGF- $\beta 1$ generation (b). Mesangial cells were grown under serum-free conditions (D-glucose concentration $5 \mathrm{mM}$ ) for $48 \mathrm{~h}$. Subsequently, aged CFSE-labelled PMNs ( $+10 \% \mathrm{FCS})$ were added for a further $3 \mathrm{~h}$ either alone or in the presence of RGDS (100 $\mu \mathrm{M})$ or antithrombospondin-1 antibody $(7 \mu \mathrm{g} / \mathrm{ml})$ for a further $3 \mathrm{~h}$. After $3 \mathrm{~h}$ of co-culture, the medium containing PMNs was removed and replaced with serum-free medium for a further $48 \mathrm{~h}$ before quantitation of TGF- $\beta 1$ in the supernatant by ELISA. In control experiments, TGF- $\beta 1$ was quantified in the supernatant taken from mesangial cells exposed to serum-free medium only for $48 \mathrm{~h}$. Data represent mean \pm s.e.m., $n=3$.
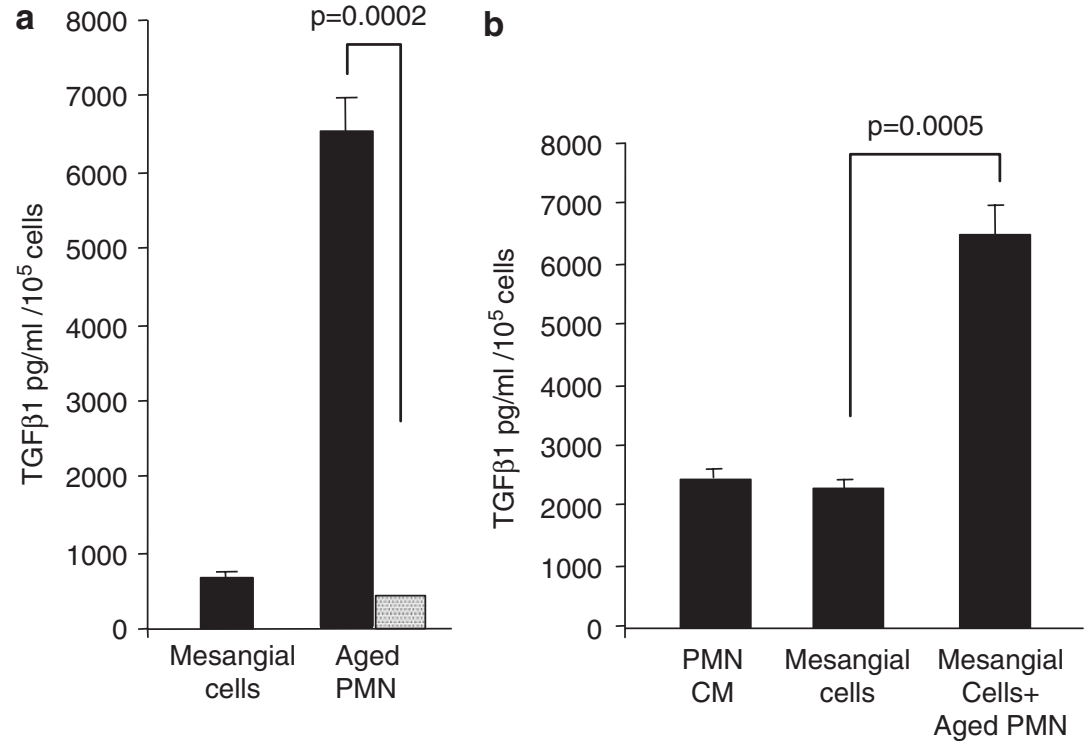

Figure 11 TGF- $\beta 1$ generation is dependent upon direct contact between mesangial and apoptotic cells. Mesangial cells were grown under serum-free conditions before addition of aged PMNs ( $+10 \%$ FCS), either directly onto the mesangial cell monolayer (solid bars) or added onto a tissue culture insert (1.0 $\mu \mathrm{m}$ pore size) to prevent direct cell-cell contact (stippled bars). In control experiments, serum-free medium alone was added to a mesangial cell monolayer. After $3 \mathrm{~h}$ of co-culture, the medium containing PMNs was removed and replaced with serum-free medium for a further $48 \mathrm{~h}$ before quantitation of TGF- $\beta 1$ in the supernatant by ELISA (a). Conditioned medium from aged PMNs has no effect on TGF- $\beta 1$ generation (b). Aged PMNs were incubated in tissue culture medium for $3 \mathrm{~h}$. The samples were centrifuged at 1600 r.p.m. and $4^{\circ} \mathrm{C}$ for $7 \mathrm{~min}$ and the supernatant was collected. Subsequently, the conditioned medium from apoptotic cells (PMN CM) was added to confluent mesangial cell monolayers for $48 \mathrm{~h}$ before quantitation of TGF- $\beta 1$ by ELISA. In control experiments, serum-free medium alone was added to a mesangial cell monolayer. A positive control was generated by addition of aged PMNs directly to mesangial cells for $3 \mathrm{~h}$ in the presence of $10 \%$ FCS before removal of PMNs and addition of serum-free medium for a further $48 \mathrm{~h}$ and quantitation of TGF- $\beta 1$. In all experiments, data represent mean \pm s.e.m., $n=3$. therefore contribute to enhanced phagocytosis. The TGF- $\beta 1$ dependent increase in phagocytosis is consistent with the demonstration in macrophages that proinflammatory cytokines including TGF- $\beta 1$ potentiate phagocytosis of neutrophils undergoing apoptosis. ${ }^{34}$ In order to examine the general applicability of our observations to non-immune cells, and more specifically to clearance of apoptotic mesangial cells by healthy mesangial cells, we have developed an in vitro system that quantitates this. The data demonstrate that as with apoptotic neutrophils, exposure of healthy mesangial cells to 
high glucose concentrations leads to enhanced clearance of apoptotic mesangial cells. This combined with our previous observations suggests that the diabetic state triggers both mesangial cell apoptosis and clearance, which both contribute to hypocellularity.

Numerous publications have demonstrated that ingestions of apoptotic cells modulates macrophage function. ${ }^{9,35}$ Much less is known regarding the response elicited by mesangial cells following interaction with apoptotic cells, although interaction between mesangial cells and apoptotic U937 cells has previously been demonstrated to stimulate mesangial cell IL-6 generation. ${ }^{29}$ A second key observation is the demonstration that the recognition of apoptotic cells by mesangial cells leads to a stimulation of TGF- $\beta 1$ generation. The data also demonstrate that direct contact between the two cell types is required to stimulate cytokine generation, as addition of conditioned medium collected from apoptotic neutrophils or separation of the two cell types in a co-culture system using tissue culture inserts failed to stimulate TGF- $\beta 1$ production. In contrast to phagocytosis of apoptotic cells, TGF$\beta 1$ generation was not dependent on the presence of serum, suggesting that this process was independent of the engulfment process but rather occurred as a result of cell-surface interactions. This is further supported by the observation that TGF- $\beta 1$ generation following co-culture of apoptotic cells and mesangial cells is independent of ambient glucose concentration, which is involved in stimulation of phagocytosis. This is consistent with previous studies, which have demonstrated $\alpha \mathrm{v} \beta 3 /$ TSP-mediated mechanisms of phagocytosis of apoptotic neutrophils by mesangial cells that was uncoupled from chemokine secretion. ${ }^{11}$ The data in the current study support the role of this recognition pathway in phagocytosis as ingestion of apoptotic cells, both immune and non-immune cells, was inhibited by the RGDS peptide and also an antibody to thrombospondin-1, although the mechanism by which TGF- $\beta 1$ influences this recognition pathway, however, remains to be defined. A similar thrombospondin-1-mediated potentiation of phagocytosis of apoptotic neutrophils by proinflammtory cytokines has been reported in macrophages. ${ }^{34}$ This increase in phagocytosis was not, however, commensurate with alterations in macrophage $\alpha \mathrm{v} \beta 3$ or thrombospondin-1, suggesting that other mechanisms of recruitment of this pathway exist, which are as yet unidentified. $^{34}$ In our study, neither the RGDS nor the thrombospondin- 1 antibody influenced TGF- $\beta 1$ generation, further supporting the concept that generation of this cytokine is separated from the phagocytosis recognition pathway. We therefore propose that binding of apoptotic cells by mesangial cells may be more important for cytokine generation than ingestion.

Previously, TGF- $\beta 1$ secretion resulting from interaction of apoptotic cells with macrophages has been associated with suppression of chemokines generation, suggesting that macrophages contribute to the resolution of inflammation not only through apoptotic cell removal but also by actively suppressing inflammatory mediator production. ${ }^{9}$ This is further supported by the observation that instillation of apoptotic cells into sites of local inflammation in the lung and peritoneum increased TGF- $\beta 1$ production and resolution of inflammation in vivo. The increase in apoptotic cells within the glomerulus in diabetes is not a consequence of inflammatory injury, but rather due to the direct stimulation of proapoptotic pathway in mesangial cells. In conclusion, we suggest that although TGF- $\beta 1$ has potent anti-inflammatory effects, in the context of diabetic nephropathy it is the profibrotic effects of TGF- $\beta 1$ that predominate. In this context, TGF- $\beta 1$ therefore has marked disease-promoting rather that disease-limiting effects.

\section{ACKNOWLEDGEMENTS}

AOP is supported by a senior Fellowship from GlaxoSmithKline. The Institute of Nephrology is supported by The Kidney Wales Foundation.

1. White KE, Bilous RW, Marshall SM, et al. Podocyte number in normotensive type 1 diabetic patients with albuminuria. Diabetes 2002;51:3083-3089.

2. Sharma K, Ziyadeh FN. Hyperglycaemia and diabetic kidney disease. Diabetes 1995;44:1139-1146.

3. Steffes MW, Osterby R, Chavers B, et al. Mesangial expansion as a central mechanism for loss of kidney function in diabetic patients. Diabetes 1989;38:1077-1081.

4. Mishra R, Emancipator SN, Kern T, et al. High glucose evokes an intrinsic proapoptotic signaling pathway in mesangial cells. Kidney Int 2005;67:82-93.

5. Kang BPS, Frencher $S$, Reddy V, et al. High glucose promotes mesangial cell apoptosis by oxidant-dependent mechanism. Am J Physiol 2003;284:F455-F466.

6. Pesce C, Menini S, Pricci F, et al. Glomerular cell replication and cell loss through apoptosis in experimental diabetes mellitus. Nephron 2002;90:484-488.

7. Haslett C. Granulocyte apoptosis and its role in the resolution and control of lung inflammation. Am J Respir Crit Care Med 1999; 160(Part 2):S5-S11.

8. Fadok VA, Bratton DL, Konowal A, et al. Macrophages that have ingested apoptotic cells in vitro inhibit proinflammatory cytokine production through autocrine/paracrine mechanisms involving TGF-beta, PGE2, and PAF. J Clin Invest 1998;101:890-898.

9. McDonald PP, Fadok VA, Bratton D, et al. Transcriptional and translational regulation of inflammatory mediator production by endogenous TGF-beta in macrophages that have ingested apoptotic cells. J Immunol 1999;163:6164-6172.

10. Savill J, Smith J, Sarraf C, et al. Glomerular mesangial cells and inflammatory macrophages ingest neutrophils undergoing apoptosis. Kidney Int 1992;42:924-936.

11. Hughes J, Liu Y, Van Damme J, et al. Human glomerular mesangial cell phagocytosis of apoptotic neutrophils. J Immunol 1997;158: 4297-4389.

12. McLoughlin RM, Witowski J, Robson RL, et al. Interplay between IFN-gamma and IL-6 signaling governs neutrophil trafficking and apoptosis during acute inflammation. J Clin Invest 2003;112:598-607.

13. Cortes-Hernandez J, Fossati-Jimack L, Carugati A, et al. Murine glomerular mesangial cell uptake of apoptotic cells is inefficient and involves serum-mediated but complement-independent mechanisms. Clin Exp Immunol 2002;130:459-466.

14. Fraser DJ, Brunskill NJ, Phillips AO. Long-term exposure of proximal tubular epithelial cells to glucose induces TGF- $\beta 1$ synthesis via an autocrine PDGF loop. Am J Pathol 2003;163:2565-2574.

15. Piek E, Moustakas A, Kurisaki A, et al. TGF-(beta) type I receptor/ALK-5 and Smad proteins mediate epithelial to mesenchymal transdifferentiation in NMuMG breast epithelial cells. J Cell Sci 1999;112(Part 24):4557-4568. 
16. Sato $Y$, Okada M, Seguchi T, et al. The mechanism for the activation of latent TGF-beta during co-culture of endothelial cells and smooth muscle cells: cell-type specific targeting of latent TGF-beta to smooth muscle cells. J Cell Biol 1993;123:1249-1254.

17. Yu Q, Stamenkovic I. Cell surface-localized matrix metalloproteinase-9 proteolytically activates TGF- $\beta$ and promotes tumor invasion and angiogenesis. Genes Dev 2000;14:163-176.

18. Munger JS, Huang $X$, Kawaskatsu $H$, et al. The integrin $\alpha v \beta 6$ binds and activates latent TGF- $\beta 1$ : a mechanism for regulating pulmonary inflammation and fibrosis. Cell 1999;96:319-328.

19. Ayo SH, Radnik RA, Garoni JA, et al. High glucose causes and increase in extracellular matrix proteins in cultured mesangial cells. Am J Pathol 1990;136:1339-1348.

20. Wolf G, Sharma K, Chen Y, et al. High glucose-induced proliferation in mesangial cells is reversed by autocrine TGF- $\beta$. Kidney Int 1992;42: 647-656.

21. Ziyadeh FN, Sharma K, Ericksen M, et al. Stimulation of collagen gene expression and protein synthesis in murine mesangial cells by high glucose is mediated by autocrine activation of transforming growth factor beta. J Clin Invest 1994:93:536-542.

22. Kreisberg Jl, Radnik RA, Ayo SH, et al. High glucose elevates c-fos and c-jun transcripts and proteins in mesangial cell cultures. Kidney Int 1994;46:105-112.

23. Kreisberg Jl, Garoni JA, Radnik R, et al. High glucose and TGF- $\beta 1$ stimulate fibronectin gene expression through a cAMP response element. Kidney Int 1994;46:1019-1024.

24. Van Det NF, Born J, Tamsma JT, et al. Effects of high glucose on the production of heparan sulfate proteoglycan by mesangial and epithelial cells. Kidney Int 1996;49:1079-1089.

25. Baker AJ, Mooney A, Hughes J, et al. Mesangial cell apoptosis: the major mechanism for resolution of glomerular hypercellularity in experimental mesangial proliferative nephritis. J Clin Invest 1994;94:2105-2116.
26. Fadok VA, Voelker DR, Campbell PA, et al. Exposure of phosphatidylserine on the surface of apoptotic lymphocytes triggers specific recognition and removal by macrophages. J Immunol 1992;148:2207-2216.

27. Savill J, Hogg N, Ren Y, et al. Thrombospondin cooperates with CD36 and the vitronectin receptor in macrophage recognition of neutrophils undergoing apoptosis. J Clin Invest 1992;90:1513-1522.

28. Savill J, Dransfiled I, Hogg N, et al. Vitronectin receptor-mediated phagocytosis of cells undergoing apoptosis. Nature 1990;343: 170-173.

29. Heidenreich $S$, Sato $T$, Schmidt $M$, et al. Induction of mesangial interleukin-6 synthesis by apoptotic U937 cells and monocytes. Kidney Int 1997;52:318-328.

30. Poczatek MH, Hugo C, Darley-Usmar V, et al. Glucose stimulation of TGF- $\beta$ bioactivity in mesangial cells is mediated by thrombospondin-1. Am J Pathol 2000;157:1353-1363.

31. Kolm-Litty V, Sauer U, Nerlich A, et al. High glucose induced transforming growth factor $\beta 1$ production is mediated by the hexosamine pathway in procine glomerular mesangial cells. J Clin Invest 1998;101:160-169.

32. Hoffman BB, Sharma K, Zhu Y, et al. Transcriptional activation of transforming growth factor-beta1 in mesangial cell culture by high glucose concentration. Kidney Int 1998;54:1107-1116.

33. Hayashida T, Schnaper HW. High ambient glucose enhances sensitivity to TGF-beta1 via extracellular signal-regulated kinase and protein kinase Cdelta activities in human mesangial cells. J Am Soc Nephrol 2004;15:2032-2041.

34. Ren Y, Savill J. Proinflammatory cytokines potentiate thrombospondinmediated phagocytosis of neutrophils undergoing apoptosis. J Immunol 1995;154:2366-2374.

35. Huynh ML, Fadok VA, Henson PM. Phosphatidylserine-dependent ingestion of apoptotic cells promotes TGF-beta1 secretion and the resolution of inflammation. J Clin Invest 2002;109:41-50. 